\title{
The Topodiverse City: Urban Form for Subjective Well-Being
}

\section{Karl Samuelsson * \\ Department of Building Engineering, Energy Systems and Sustainability Science, University of Gävle, Gävle, Sweden}

Research is now better than ever able to unveil how urban inhabitants' movement, behavior and experiences relate to the urban forms in which they take place. Consequently, urban form might increasingly be able to function as a focal point for different strands of research that focus on sustainable urban life, and as a link between research and planning practice through the development of empirically informed design principles. Drawing on literature from urban morphology, complex systems analysis, environmental psychology, and neuroscience, I provide a wide-angle view of how urban form relates to subjective well-being through movement, social and economic activity, experiences and psychological restoration. I propose three principles for urban form that could promote subjective well-being while also mitigating the environmental impact of cities in industrialized societies. The principles revolve around so-called topodiversity, meaning variation across an urban area in spatial conditions that allows subjective well-being to be promoted through several different pathways. The principles together suggest an urban form that I call the topodiverse city. The topodiverse city displays a polycentric structure and is more spatially contained than the sprawling city, yet not as compact as the dense city. I also propose indicators to measure the principles using mostly openly available data and analysis methods, to further research on how urban form can enable urban subjective well-being with low environmental impact.

Keywords: urban morphology, complex adaptive systems, urban resilience, affordances, social-ecological urbanism, densification, restorative experiences

\section{INTRODUCTION}

The world is both urbanizing and on an unsustainable trajectory. Consequently, industrialized societies must urgently address the dual issues of catering to the urban populations' well-being and ease the cities' pressure on the planet. Urban form can constitute a key leverage point; it matters for many physical health outcomes (Goines and Hagler, 2007; Tan et al., 2010; Marshall et al., 2014; Sarkar et al., 2017; Borck and Schrauth, 2021) and many mental health outcomes (Evans, 2003; Barros et al., 2019; Hunter et al., 2019). It also matters for mitigating climate change (Creutzig et al., 2015; Güneralp et al., 2017; Barrington-Leigh and Millard-Ball, 2020) and the sixth mass extinction (Seto et al., 2012). The aim of this paper is to propose measurable principles for urban form that promotes subjective well-being and at the same time align with efforts to mitigate cities' environmental impacts. Subjective well-being is an important part of human well-being (Dolan and Metcalfe, 2012) that encompasses affective and cognitive processes (Pavot and Diener, 2013) and can be conceived as resulting from an individual's resources and challenges in the psychological, social and physical domains (Dodge et al., 2012). There is a long tradition in urban discourse to implicitly adhere to this conception of subjective well-being by describing city life as integrated social 
and psychological phenomena that play out across physical space. In 1903, Simmel described how the intensification of economic activity and environmental stimuli in the rapidly growing metropolises of its day caused behavioral adaptations in the social domain (Simmel, 2002). Wirth (1938) outlined the sociological concept of city in which personal relationships are partly replaced by institutions catering to the masses. Milgram (1970) argued for adaptation to sensory overload as the mechanism behind the emergence of specifically urban behaviors, such as allocating little time to each interpersonal interaction. These works constitute milestones in a line of thinking centered around the tension between social and economic resources and psychological challenges in urban life.

There is also a long tradition in urban discourse of prescribing idealized urban forms that aim to balance the social and economic opportunities of city life with access to health-promoting open space. This was true of the garden city movement (Howard, 2007), as part of which Perry (1929) devised the neighborhood unit plan that was the model for several designs by architects Henry Wright and Clarence Stein. It was also true of the modernist school of thought, in which Le Corbusier developed a vision of a city of towers encircled by parkland that would meet the needs of modern business while avoiding the noise and pollution associated with pre-modern cities (Le Corbusier, 1986). However, propositions such as these largely disregarded existing spatial and social dynamics, the dangers of which was best expressesd by Jacobs (1961) in The Death and Life of Great American Cities. As a counterpoint to idealized prescriptions for urban form, space syntax (Hillier et al., 1976) emerged as an analytical framework to systematize descriptions of urban space by studying how human settlements evolve bottom-up. The approach convincingly revealed how the ways in which humans configure space manifest a social logic that embeds social and economic processes, and that such dynamic processes can in part be captured by static descriptions of urban form (Hillier and Hanson, 1984; Hillier et al., 1993).

The development of space syntax research has been part of a general surge in recent decades in quantitative spatial analysis of cities that have extended beyond urban form alone and into areas more directly related to subjective well-being. Recent methodological advances have resulted in rich quantitative evidence for how people move through, behave in and experience urban space. Thus, urban form might increasingly be able to function as a focal point for different strands of research that deal with sustainable urban life. Moreover, research can be better linked with planning practice through the development of empirically informed principles for urban form. In cities in industrialized societies where urban landscapes are largely shaped by formal planning processes, such empirical principles could serve an urban planning paradigm aiming to promote inhabitants' subjective well-being as well as ease cities' pressure on the planet. To underpin the principles I propose here, I synthesize in a non-systematic review recent findings from urban morphology, complex systems analysis, environmental psychology, and neuroscience. This literature is presented as three different perspectives on urban form and subjective wellbeing: the socio-spatial perspective, the psychological perspective and the bird's eye perspective. The integration of perspectives in this text means that it cannot present all the intricacies of any particular research area; the purpose is instead to make manifest relations between different phenomena relating to subjective well-being in urban life. I then present three principles revolving around the concept topodiversity, and how they together suggest an urban form that I call the topodiverse city. Lastly, I propose some indicators that can be used to measure the principles and the relevant outcomes related to them.

\section{THE SOCIO-SPATIAL PERSPECTIVE: STREET NETWORKS, MOVEMENT, AND ECONOMIC ACTIVITY}

Cities are about facilitating human interaction in physical space (Batty, 2012). The primary medium of this is the street network, where those spaces that facilitate interaction can be thought of as a foreground network contrasted against a background network of mainly residential space (Hillier et al., 2009). Humans do not roam a street network randomly: research rooted in complex systems analysis has shown that they tend to move between a few select places that together make up an activity set and where the visitation frequency of places follow a power law distribution (González et al., 2008). This conserved range of mobility means that as humans explore novel places there is a possibility that these places become part of the activity set while familiar places are dropped from it, and so the activity set evolves over time (Alessandretti et al., 2018a). The size of the activity set and the degree to which one engages in exploration varies considerably between individuals, and covaries with personality traits like extraversion (Alessandretti et al., 2018b); however, many dayto-day activity sets encompass $\sim 25$ places (Alessandretti et al., 2018a).

The locations of places in the activity set together with routes between them constitute an activity space (Cagney et al., 2020). Just as activity place set sizes varies between individuals, so does activity space sizes (Hasanzadeh et al., 2018). An early observation in space syntax research was that movement between places tends to occur along the topologically shortest route connecting those places, or in other words that people tend to make as few turns as possible (Hillier et al., 1993). More recent studies have achieved better predictions by weighting turns by their angles, meaning that people tend to take routes where the total sum of angular direction change is minimized; this has for example been verified by microscale tracking of $\sim 2$ million urban pedestrian trips through mobile phone wi-fi signals (Stavroulaki et al., 2019). Corroborating evidence has also been uncovered through neuroimaging that reveals how during navigation in a city some parts of the hippocampus track changes in local topology while other parts track the current place's prominence in the global network (Javadi et al., 2017). Such tracking is possible because the visual system continuously identifies possibilities for moving across the environment (Bonner and Epstein, 2017), or in other words links in the topological network. Topological structure is crucial for navigation because it answers the question "From the current 
place, which other places can I move to?" This means that topologically central places will be more attractive locations for example when establishing a business, as more movement en route to other places will happen there. Thus, the distribution of destinations often acts as a multiplier of the movement patterns generated by the street network (Hillier et al., 1993).

Street network characteristics also influence travel mode choices. On this topic, little research has focused on topological street network structure. However, networks with high intersection density (which is not a topological measurement) favor walking and biking (hereafter "active movement") (Marshall and Garrick, 2010). In fact, such street network characteristics seem to matter more than residential or job density (Ewing and Cervero, 2010). In industrialized societies, less connected street networks and lower built densities are independently associated with higher degree of car ownership (Barrington-Leigh and Millard-Ball, 2019). Thus, how the street network is designed will influence the activity spaces of individuals (Parthasarathi et al., 2015), both directly by determining modes of transport and routes taken for travelling between places, and indirectly by what spaces it privileges for establishing economic or social activity. Furthermore, because humans have a limited mobility range (Alessandretti et al., 2018a), these activity spaces will be "sticky" once they form. This makes the configuration of the street network a powerful tool in the structuring of urban social and economic life.

\section{THE PSYCHOLOGICAL PERSPECTIVE: INDIVIDUALS' EXPERIENCES AND SUBJECTIVE WELL-BEING}

The previous section describes a positive feedback loop: where more people move, more activity will take place, making even more people move there. This is reflected in aggregated movement flows being exponentially related to the topological centrality of streets (Hillier et al., 1993). Characteristics at the systemic level thus feed back to the local place level in that the flow of people will influence an individual's experience. For example, in Stockholm's areas of high topological centrality, experiences with negative valence, often related to crowding, dominate (Samuelsson et al., 2019). This is what Milgram (1970) argued specifically urban behaviors to be an adaptation towards. Yet, such adaptations might not always be sufficient to cope with environmental demands. Appraisal of the environment can cause a psychophysiological stress response if the situation is perceived to frustrate control or contain the possibility of negative social evaluation (Dickerson and Kemeny, 2004). The intimate connection between city life and a social stress response is corroborated by experimental evidence (Lederbogen et al., 2011) exposure to concentrated movement flows could be a key factor for this connection (Samuelsson et al., 2019). New methods utilizing smartphones and other wearable sensors for tracking people moving through urban environments while collecting subjective and objective indicators of their experiences (e.g. Shoval et al., 2018; Torku et al., 2021) could, if combined with street network measurements, further research around what the systemic spatial conditions are that create stress in urban life.

Seeking out environments with a relative absence of stressors, which in modern cities often correspond to natural settings, allows for affective and cognitive restoration (Hartig et al., 2003). Out of the many health benefits of nature experience that research has highlighted, the restoration pathway is one of the most central and well established (Markevych et al., 2017). For example, spending an hour in natural settings in one's daily urban life reduces salivary stress hormone concentrations by about $20 \%$ (Hunter et al., 2019). The benefits of nature experience for subjective well-being has contributed to a growing interest in urban greening and biophilic urbanism, a design approach that seeks to integrate natural elements with the built urban fabric and erase the unhelpful dichotomy between city and nature (Reeve et al., 2015). Such design approaches hold great potential for reducing stress responses at or close to their source (De Vries et al., 2013), and for improving other urban ecosystem services (Abhijith et al., 2017; Kong et al., 2017), and should consequently be a key urban redesign priority. Nevertheless, a requirement of fully restorative environments is that they provide getting away from one's routine (Hartig et al., 2003), so it comes as no surprise that restorative experiences happen in areas with the least topological centrality (Samuelsson et al., 2019). In other words, urban inhabitants often have to literally go out of their way for restorative experiences. Depending on urban form, this requires different amounts of effort for the individual seeking restoration.

Taken together, the above paragraphs paint a gloomy picture of urban life. Yet, cities are celebrated for concentrating a wide variety of people and activities. In this vein, longitudinal data shows that experiencing different places in a day leads to positive affect in individuals, especially if these places are sociodemographically varied (Heller et al., 2020). Furthermore, there seems to be a feedback relationship in that positive affect also encourages people to seek out novel environments (Heller et al., 2020). Street network configuration underpins possibilities for social co-presence in public space (Legeby, 2013). Furthermore, active movement, compared with driving or public transport, invite richer sense experiences of the routes traveled and interactions with the environment that can build social connectedness (Brömmelstroet et al., 2017). Active movement is also related to more positive mood compared with motorized transport (Glasgow et al., 2019), but it remains to be researched how transportation mode mediates associations between environmental diversity and subjective well-being. Across different people, the diversity of kinds of experience within the same neighborhood is greatest in areas of intermediate centrality, as opposed to the most connected areas that are dominated by negative experiences (Samuelsson et al., 2019). Such evidence suggests the possibility of urban environments that promote subjective well-being through access via active movement to the cities' varied social and economic resources while avoiding the psychological toll of crowding. 


\section{THE BIRD'S EYE PERSPECTIVE: EMERGENT MACROSCALE PATTERNS}

In complex adaptive systems, such as cities (Batty, 2009), emergent properties arise from local interactions (Levin, 1998). With increasing availability of very large datasets on various aspects of cities and urban life, there has been a growing interest in recent years of extracting "universal laws" out of the emergent properties arising from local social and economic interactions. While we cannot expect to ever reduce geographical phenomena to fully replicable laws (Goodchild and $\mathrm{Li}, 2021$ ), it is helpful to uncover links between the eye level view of the inhabitant and the bird's eye view because it 1 ) helps understanding what processes that give rise to specific urban forms, and 2) is a requisite for complexity-based empirically informed ideas about urban form that answer to the outcomes we care about.

Again, cities' reason for being are facilitation of human interaction in physical space (Batty, 2012). This is reflected in urban scaling laws: street network length scales sub-linearly with population size whereas social and economic activity scale superlinearly (Bettencourt, 2013). These spatial interaction effects enable coordination of knowledge that explains why complex economic activities concentrate in large cities (Balland et al., 2020).

Infrastructure length and socioeconomic activity also scale in a hierarchical way among the sub-areas within cities, which can be explained by spatial autocorrelation of socioeconomic activity (Dong et al., 2020). In other words, the positive feedback mechanism that activity attracts further activity shows up yet again. The relative configurational properties of street networks within this hierarchical arrangement tend to remain constant with changing city size (Hillier et al., 1993), suggesting that hierarchical scaling maintains the street network's ability to continue to facilitate human interaction in the face of growth. These observations are in line with a recently proposed visitation law of human mobility (Schläpfer et al., 2021). The authors find hierarchical spatial clustering of economic activity arising from individuals' movement being constrained in space and time and simultaneously coupled with each other (i.e. activity attracts further activity) (Schläpfer et al., 2021). This explains why many cities, especially those dating from pre-modern eras, display macroscale fractal morphologies (Makse et al., 1995); a fractal form arises as an emergent property resulting from decentralized self-organization because it gives more interaction bang for the spatiotemporally constrained travel buck. Thus, human mobility is not scale-free; it is structured in "spatial containers" that correspond well to intuitive conceptions of neighborhood, city, metropolitan area and region (Alessandretti et al., 2020). The same spatial scales can be found in the topological configuration of street networks (Berghauser Pont et al., 2017). These findings are reminiscent of central place theory (Christaller, 1933), a conjecture in geography which similarly posits that a spatial hierarchical clustering of economic centers optimizes traveling among a population.

In summary, a convincing body of evidence now indicates that urban systems self-organize towards maximization of human interaction given travel costs. Yet, this does not necessarily equate a desired output in terms of human well-being, as the section on the psychological perspective above illustrates. Neither does it necessarily equate mitigation of cities' impacts on the planet. I now turn my attention to how urban form can contribute to these dual outcomes.

\section{TOPODIVERSITY: DEFINITION, THREE PRINCIPLES AND THE URBAN FORM THEY SUGGEST}

The story so far has been one of urban form emerging bottom-up from local interactions. While this is how pre-modern cities grew, urban development in industrialized societies is just as much about top-down urban planning interventions. Modernism's all too heavy-handed counteractions towards urban bottom-up dynamics was a central theme in Jane Jacobs' classic The Death and Life of Great American Cities (Jacobs, 1961). A better paradigm in urban planning should work in accord with the central dynamics of cities' emergence. The research recounted in the preceding three sections illustrates a few broad categories of system component that produce these dynamics. There is a mutualism of co-evolving network and destinations. This co-evolution influences movement flows. Furthermore, it takes place in a geographic context, including a natural landscape that the network can provide access to or shield people off from. These components together create spatial conditions for environments to support subjective well-being (Samuelsson, 2021), where certain spatial conditions support subjective wellbeing through certain pathways. For example, spatial conditions in the foreground network better support well-being through possibilities to partake in social and economic activity (cf. Hillier et al., 2009) whereas those in the background network better support well-being through restoration.

I propose the term topodiversity (from the Greek topos meaning place) to refer to variation across an urban area in such spatial conditions that matter for subjective well-being, so that it can be promoted through several different pathways (Samuelsson, 2021). The term highlights how distinct places support subjective well-being but that the ways in which they do so is conditioned on them being parts of a larger spatial system. Urban planning should shape urban form so as to improve or maintain topodiversity while at the same time limit cities' environmental impacts. It is with these dual goals in mind that I outline three general principles for topodiversity below, before illustrating how they together suggest an urban form that I call the topodiverse city and compare it to the dense city and the sprawling city.

\section{Principle 1: Avoid Street Network Sprawl}

Principle 1 is to ensure that people through active movement can use urban environments as a resource to support their subjective well-being. Even though they are mutualistic, street network configuration and distribution of destinations are separate dimensions of environments' ability to uphold street life (Berghauser Pont et al., 2019), and of travel mode choices 
(Ewing and Cervero, 2010; Barrington-Leigh and Millard-Ball, 2019). However, while most literature on sprawl focuses on density of people or buildings, the street network provides the greater leverage as it is the main generator of activity on which the distribution of destinations can act as a multiplier (Hillier et al., 1993). Attempting to stimulate active movement through densification of built structure on a street network favoring driving is an uphill struggle. Barrington-Leigh and MillardBall, 2019 developed a global measurement of street network sprawl (SNDi), where high values indicate lots of dead-ends and winding roads. This suggests that avoiding street network sprawl is a matter of providing four-way intersections and making sure streets are part of relatively straight-forward loops to allow different routes between the same places. This is strikingly similar to what Jacobs (1961) proposed for achieving an active street life. Note that avoiding street network sprawl does not necessarily implicate constructing regular street grids: low street network sprawl is highly correlated with regular grids in USA, but other types of low-sprawl networks exist elsewhere in the world (Barrington-Leigh and Millard-Ball, 2019). If sprawl is avoided in the networks for active movement, i.e. pedestrian and bicycle paths, overall street network sprawl might constitute less of a concern. For example, Denmark has since 2000 seen decreasing connectivity in their motor traffic networks but increasing connectivity in their bike networks (Barrington-Leigh and Millard-Ball, 2020), which has likely contributed to the rapid increase in bike trips during the same period (Kaaronen and Strelkovski, 2020). Avoiding street network sprawl synergizes with other key environmental issues related to urban development, like halting encroachment on agricultural lands (Bren d'Amour et al., 2017; Barthel et al., 2019) and ecosystem service-providing ecosystems (Seto et al., 2012; Pan et al., 2021).

\section{Principle 2: Avoid Too High Concentrations of People}

Principle 2 is to ensure that the psychological demands of urban life do not outweigh the benefits derived from social and economic resources, and thus constitutes balancing the reinforcing feedback loop that activity attracts further activity. This principle is focusing on what should be avoided rather than what should pursued, because people are more diverse with regards to their positive experiences than their negative ones (Samuelsson et al., 2019). Importantly, concentration of people as used here refers not just to the residential population, but also daytime population and those passing through en route to other places. Complementary strategies to manage concentration of people in this sense relate to the network and the destinations, respectively. Most obviously, avoiding spatial concentration of destinations above some threshold sets a boundary for tomovement. The functional mix of destinations, for example between housing and places for daytime activity, also matters (Ahern, 2011), as this influences whether the movement all happens during specific parts of the day or throughout it. Mixed-use neighborhoods will have lower concentration spikes than monofunctional ones of similar density, and so contain fewer negative experiences of crowding (Samuelsson et al., 2019).
A less obvious strategy is to avoid street networks where some streets have a topological centrality above some threshold, because this together with the distribution of destinations sets the boundary for through-movement. These thresholds likely vary between cities with different cultural and geographical contexts and could also change for the same city with time. Future research should focus on how these thresholds interact to produce or avoid psychological challenges in different contexts. Yet, as argued above in the section on the psychological perspective, it is evident that one or both are crossed in central areas in many of the world's cities today.

Implementation of this principle would, perhaps controversially, curb or even reverse development in many cities' central areas. In isolation, it could counteract Principle 1 , as in the case of India's restriction of building heights causing spatial expansion of cities (Brueckner and Sridhar, 2012; Barrington-Leigh and Millard-Ball, 2020), illustrating the need for comprehensive urban planning policies based on systems thinking. Yet, as people will self-organize within an urban form towards optimal collective traveling (Schläpfer et al., 2021), an emergent self-organized urban form with boundaries imposed top-down on both street network sprawl and concentrations of active populations could achieve a balance between supporting social and economic activity and avoiding detrimental psychological consequences.

\section{Principle 3: Provide Topodiversity on the Neighborhood Scale}

Principle 3 ensures that people can form local activity spaces that support subjective well-being through experience diversity (Heller et al., 2020) within a conserved movement range (Alessandretti et al., 2018a) through active movement that eases cities' pressure on the Earth system. The principle first requires that the neighborhood scale is defined. Differing movement capabilities between people means that it is not absolute and fixed. Nevertheless, literate has found that active movement is mostly used for trips shorter than $2.5 \mathrm{~km}$ (Kaplan et al., 2016; Hasanzadeh et al., 2017). This is close to $\sim 3 \mathrm{~km}$ (straight line distance) that Alessandretti et al. (2020) found to be the typical size of the smallest mobility container. It is also in agreement with the $2.5-3 \mathrm{~km}$ (street network distance) that (Berghauser Pont et al., 2017) found to be the breakpoint between the neighborhood and city scales in four cities' topological networks, providing a good indication that metric street network distance often can be used as a meaningful heuristic measurement for topological distance. Note that this principle does not suggest that everything a city has to offer should be present in each of its neighborhoods; city-wide movement will always be crucial for cities' ability to facilitate complex economic activity (cf. Balland et al., 2020) and contribute to differentiation between neighborhoods.

While urban planning cannot and should not attempt to engineer the social lives of people (Jacobs, 1961), it sets the boundary conditions of kinds of environment within which people construct their activity spaces. More topodiversity on the neighborhood scale entails opportunities for more people's local activity spaces to evolve 


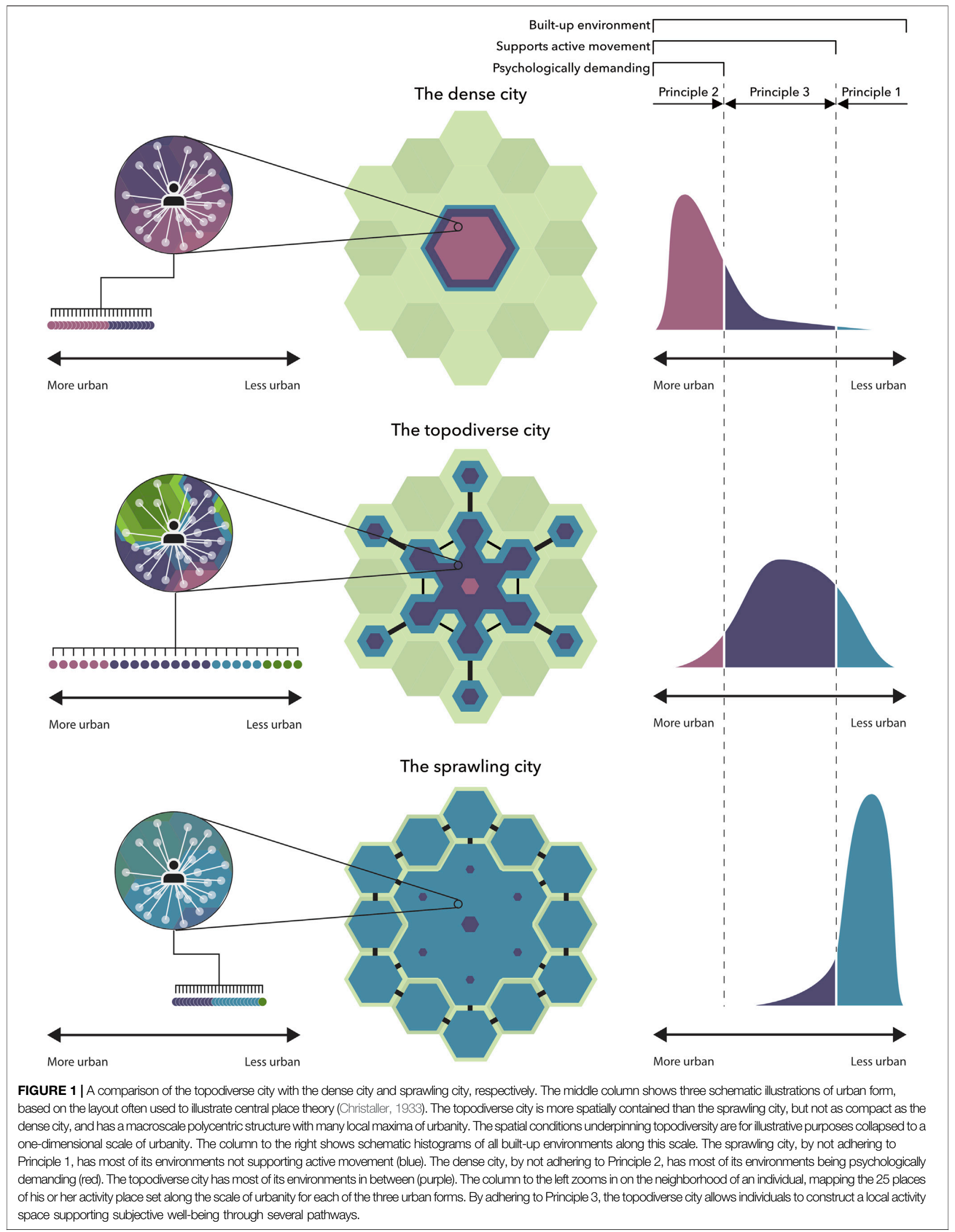


in more desirable directions. Thus, urban planning should strive towards providing neighborhood-scale variation in the components that constitute spatial conditions for subjective well-being, i.e. centrality of street segments (both within-neighborhood and at the city scale), density of destinations (residential and daytime), and presence of natural settings. Design has the potential to regulate the extent to which these components co-exist; the spatial conditions are thus multidimensional. Nevertheless, they are bound to covary to some degree, meaning that the spatial conditions likely have a clear main dimension corresponding to the division between the foreground and background networks (Hillier et al., 2009). Principle 3 thus includes that the dynamic between the foreground and background networks should be present on the neighborhood scale. Analogues to neighborhood-scale topodiversity could be found in examples ranging from preindustrial market towns (Hillier and Hanson, 1984) to the "15min city" proposed as a post-COVID-19 urban planning vision (Sisson, 2020).

\section{The Topodiverse City}

The three principles in combination suggest that a kind of urban form I call the topodiverse city better answers to the dual issues of promoting subjective well-being and limiting the city's environmental impacts, compared with the dense city and the sprawling city (Figure 1). I ask the reader to be mindful of that Figure $\mathbf{1}$ is only a schematic illustration that is not meant to capture all the complexity of actual cities. For illustrative purposes, the multidimensional spatial conditions constituted by street network configuration, distribution of destinations, and the natural landscape are in the figure collapsed to a onedimensional scale of urbanity.

The sprawling city (bottom row of Figure 1) does not satisfy Principle 1, while the dense city (top row of Figure 1) does not satisfy Principle 2. The topodiverse city (middle row of Figure 1), by satisfying the first two principles, better manages to avoid both environments that cannot support active movement and those that are psychologically demanding. The right side of the figure illustrates this through histograms of all built-up environments along the scale of urbanity for the three urban forms. Satisfying both Principle 1 and Principle 2 means that the topodiverse city has a macroscale form that is more spatially contained than the sprawling city, but not as compact as the dense city. Adherence to Principle 3 means that individuals will have a greater diversity of environments to construct a local activity space from, compared with both the dense city and the sprawling city. The left side of the figure illustrates this by zooming in on the neighborhood of an individual, mapping the 25 places of his or her activity place set along the scale of urbanity for each of the three urban forms. This leads to the topodiverse city having a macroscale polycentric structure with many local maxima of urbanity.

\section{Measuring the Principles and Relevant Outcomes}

The literature that this paper synthesizes suggests that the principles together promote subjective well-being while limiting environmental impacts, but no comprehensive study has yet been undertaken. Future research can accomplish this by focusing on integration of already existing methods for data collection and analysis. Fulfillment of Principle 1 can be measured using SNDi (Barrington-Leigh and Millard-Ball, 2019), as this measurement only uses as input openly available street segment data from OpenStreetMap, a highly reliable data source for industrialized societies (Barrington-Leigh and MillardBall, 2017). Moreover, SNDi considers a spatial bandwidth of $3,000 \mathrm{~m}$, which happens to comply with the relevant neighborhood size for active movement. Fulfillment of Principle 2 can be measured by combining 1) residential population density, 2) daytime population density, and 3) a proxy for through-movement population density, for example angular betweenness of street segments (Hillier et al., 2012). Fulfillment of Principle 3 would be measured with the same variables as fulfillment of Principle 2, together with an indicator of presence of natural settings (for example the Normalized Difference Vegetation Index (NDVI) calculated using openly available remotely sensed satellite images). Topodiversity could be operationalized for example as the multivariate variance of these variables among places in a neighborhood.

Smartphones equipped with GPS sensors and accelerometers can measure individuals' transportation mode choices (Byon and Liang, 2014) and local activity spaces (Alessandretti et al., 2018a; Heller et al., 2020) and relate them to urban form. Extrapolating from associations between urban form and movement allows for relating the principles to transportation energy use. The principles can further be linked to individuals' subjective well-being in day-today life. Subjective well-being can be estimated either by individuals themselves through geocoded surveys taken in the moment (e.g. MacKerron and Mourato, 2013) or retrospectively (e.g. Kyttä et al., 2016), or with more "objective" indicators including physiological measurements recorded by wearable devices (e.g. Shoval et al., 2018) and salivary biomarkers (e.g. Hunter et al., 2019). All these methods have their respective strengths and weaknesses, and combination of several methods is likely to yield more reliable overall estimations.

Lastly, fulfillment of the principles in places and neighborhoods can be related to macroscale measurements of urban form, such as spatial extent, compactness and polycentricity. This would serve two purposes. First, it would allow understanding how the principles together are connected to environmental issues related to urban expansion, such as encroachment on biodiverse lands (Seto et al., 2012). Second, it would allow large-scale master planning of cities and meso-scale planning of neighborhoods to harmonize around the dual issues of improving inhabitants' wellbeing and mitigating environmental impact.

\section{CONCLUDING REMARKS}

Keeping an increasingly urban civilization healthy and happy within environmental planetary boundaries requires urban environments that allow both for sustainable social and economic interaction and psychological restoration, the ebb and flow of urban life. Frameworks that lead the way should be malleable enough for context-sensitive application in urban planning, yet rigorous enough to lend themselves to scientific 
inquiry. I have proposed three principles along these lines, revolving around the concept topodiversity, that are intended to balance sprawling and concentrating forces in cities (Principle 1 and Principle 2), and ensure support of subjective well-being through multiple pathways on the neighborhood scale (Principle 3 ). The principles together point towards the topodiverse city as a desirable urban form distinct from both the dense city and the sprawling city. Nevertheless, the principles are far from suggesting rigid idealized solutions that disregard existing dynamics; they rather stake out a direction for stepwise development based on the context and the socio-spatial system of the city. Importantly, fulfilment of the principles can also be measured using data and methods that are already existing and to a large extent openly available. The principles can consequently be related to actual movement and subjective well-being through ubiquitous technology like smartphones. Such methodological integration finally allows a sort of quantitative and analytic succession to classical works like those by Simmel (2002), Wirth (1938), Jacobs (1961), and Milgram (1970). I hope to see future research investigate how the principles hold up under scrutiny, and more closely determine what spatial organizations characterize the topodiverse city in different contexts.

\section{REFERENCES}

Abhijith, K. V., Kumar, P., Gallagher, J., McNabola, A., Baldauf, R., Pilla, F., et al. (2017). Air Pollution Abatement Performances of green Infrastructure in Open Road and Built-Up Street canyon Environments - A Review. Atmos. Environ. 162, 71-86. doi:10.1016/j.atmosenv.2017.05.014

Ahern, J. (2011). From Fail-Safe to Safe-To-Fail: Sustainability and Resilience in the New Urban World. Landscape Urban Plann. 100 (4), 341-343. doi:10.1016/ j.landurbplan.2011.02.021

Alessandretti, L., Aslak, U., and Lehmann, S. (2020). The Scales of Human Mobility. Nature 587 (7834), 402-407. doi:10.1038/s41586-020-2909-1

Alessandretti, L., Lehmann, S., and Baronchelli, A. (2018b). Understanding the Interplay between Social and Spatial Behaviour. EPJ Data Sci. 7 (1). doi:10.1140/ epjds/s13688-018-0164-6

Alessandretti, L., Sapiezynski, P., Sekara, V., Lehmann, S., and Baronchelli, A. (2018a). Evidence for a Conserved Quantity in Human Mobility. Nat. Hum. Behav. 2 (7), 485-491. doi:10.1038/s41562-018-0364-x

Balland, P.-A., Jara-Figueroa, C., Petralia, S. G., Steijn, M. P. A., Rigby, D. L., Hidalgo, C. A., et al. (2020). Complex Economic Activities Concentrate in Large Cities. Nat. Hum. Behav. 4 (3), 248-254. doi:10.1038/s41562-0190803-3

Barrington-Leigh, C., and Millard-Ball, A. (2019). A Global Assessment of StreetNetwork Sprawl. PLoS ONE 14 (11), e0223078-16. doi:10.1371/ journal.pone.0223078

Barrington-Leigh, C., and Millard-Ball, A. (2017). The World's User-Generated Road Map Is More Than 80\% Complete. PLoS ONE 12 (8), e0180698-20. doi:10.1371/journal.pone.0180698

Barrington-Leigh, C., and Millard-Ball, A. (2020). Global Trends toward Urban Street-Network Sprawl. Proc. Natl. Acad. Sci. USA 117 (4), 1941-1950. doi:10.1073/pnas.1905232116

Barros, P., Ng Fat, L., GarciaGarcia, L. M. T., Slovic, A. D., Thomopoulos, N., de Sá, T. H., et al. (2019). Social Consequences and Mental Health Outcomes of Living in High-Rise Residential Buildings and the Influence of Planning, Urban Design and Architectural Decisions: A Systematic Review. Cities 93, 263-272. doi:10.1016/j.cities.2019.05.015

Barthel, S., Isendahl, C., Benjamin, N. V., Drescher, A., Evans, D. L., and van Timmeren, A. (2019). Global Urbanization and Food Production in Direct

\section{DATA AVAILABILITY STATEMENT}

The original contributions presented in the study are included in the article/Supplementary Material, further inquiries can be directed to the corresponding author.

\section{AUTHOR CONTRIBUTIONS}

The author confirms being the sole contributor of this work and has approved it for publication.

\section{FUNDING}

This paper is based on work funded by Formas (grant no 201601193) and the University of Gävle.

\section{ACKNOWLEDGMENTS}

Thanks to Stephan Barthel for feedback on a draft version of the manuscript.

Competition for Land: Leverage Places to Mitigate Impacts on SDG2 and on the Earth System. Anthropocene Rev. 6 (1-2). doi:10.1177/2053019619856672

Batty, M. (2012). Building a Science of Cities. Cities 29, 9-16. doi:10.1016/ j.cities.2011.11.008

Batty, M. (2009). "Cities as Complex Systems: Scaling, Interactions, Networks, Dynamics and Urban Morphologies," in The Encyclopedia of Complexity \& System Science (Berlin: Springer).

Berghauser Pont, M., Stavroulaki, G., Gil, J., Marcus, L., Serra, M., Hausleitner, B., et al. (2017). "Quantitative Comparison of Cities: Distribution of Street and Building Types Based on Density and Centrality Measures," in Proceedings of the 11th Space Syntax Symposium, 3-7 July 2017, Lisbon, Portugal.

Berghauser Pont, M., Stavroulaki, G., Marcus, L., and Marcus, Lars. (2019). Development of Urban Types Based on Network Centrality, Built Density and Their Impact on Pedestrian Movement. Environ. Plann. B: Urban Analytics City Sci. 46 (8), 1549-1564. doi:10.1177/2399808319852632

Bettencourt, L. M. A. (2013). The Origins of Scaling in Cities. Science 340 (6139), 1438-1441. doi:10.1126/science. 1235823

Bonner, M. F., and Epstein, R. A. (2017). Coding of Navigational Affordances in the Human Visual System. Proc. Natl. Acad. Sci. USA 114 (18), 4793-4798. doi:10.1073/pnas.1618228114

Borck, R., and Schrauth, P. (2021). Population Density and Urban Air Quality. Reg. Sci. Urban Econ. 86 (February 2020), 103596. doi:10.1016/ j.regsciurbeco.2020.103596

Bren d'Amour, C., Reitsma, F., Baiocchi, G., Barthel, S., Güneralp, Erb, B. K-H., Haber, H., et al. (2017). Future Urban Land Expansion and Implications for Global Croplands. Proc. Natl. Acad. Sci. 114 (34), 201606036.

Brömmelstroet, M. t., Nikolaeva, A., Glaser, M., Nicolaisen, M. S., and Chan, C. (2017). Travelling Together Alone and Alone Together: Mobility and Potential Exposure to Diversity. Appl. Mobilities 2 (1), 1-15. doi:10.1080/ 23800127.2017.1283122

Brueckner, J. K., and Sridhar, K. S. (2012). Measuring Welfare Gains from Relaxation of Land-Use Restrictions: The Case of India's Building-Height Limits. Reg. Sci. Urban Econ. 42 (6), 1061-1067. doi:10.1016/ j.regsciurbeco.2012.08.003

Byon, Y.-J., and Liang, S. (2014). Real-time Transportation Mode Detection Using Smartphones and Artificial Neural Networks: Performance Comparisons between Smartphones and Conventional Global Positioning System Sensors. 
J. Intell. Transportation Syst. 18 (3), 264-272. doi:10.1080/ 15472450.2013 .824762

Cagney, K. A., York Cornwell, E., Goldman, A. W., and Cai, L. (2020). Urban Mobility and Activity Space. Annu. Rev. Sociol. 46, 623-648. doi:10.1146/ annurev-soc-121919-054848

Christaller, W. (1933). Die Zentralen Orte in Süddeutschland. Jena: Gustav Fischer.

Creutzig, F., Baiocchi, G., Bierkandt, R., Pichler, P.-P., Seto, K. C., and Seto, K. C. (2015). Global Typology of Urban Energy Use and Potentials for an Urbanization Mitigation Wedge. Proc. Natl. Acad. Sci. USA 112 (20), 6283-6288. doi:10.1073/pnas.1315545112

De Vries, S., van Dillen, S. M. E., Groenewegen, P. P., and Spreeuwenberg, P. (2013). Streetscape Greenery and Health: Stress, Social Cohesion and Physical Activity as Mediators. Soc. Sci. Med. 94, 26-33. doi:10.1016/ j.socscimed.2013.06.030

Dickerson, S. S., and Kemeny, M. E. (2004). Acute Stressors and Cortisol Responses: A Theoretical Integration and Synthesis of Laboratory Research. Psychol. Bull. 130 (3), 355-391. doi:10.1037/0033-2909.130.3.355

Dodge, R., Daly, A., Huyton, J., and Sanders, L. (2012). The challenge of Defining Wellbeing. Intnl. J. Wellbeing 2 (3), 222-235. doi:10.5502/ijw.v2i3.4

Dolan, P., and Metcalfe, R. (2012). Measuring Subjective Wellbeing: Recommendations on Measures for Use by National Governments. J. Soc. Pol. 41 (2), 409-427. doi:10.1017/s0047279411000833

Dong, L., Huang, Z., Zhang, J., and Liu, Y. (2020). Understanding the Mesoscopic Scaling Patterns within Cities. Sci. Rep. 10 (1), 21201-21211. doi:10.1038/ s41598-020-78135-2

Evans, G. W. (2003). The Built Environment and Mental Health. J. Urban Health Bull. New York Acad. Med. 80 (4), 536-555. doi:10.1093/jurban/jtg063

Ewing, R., and Cervero, R. (2010). Travel and the Built Environment. J. Am. Plann. Assoc. 76 (3), 265-294. doi:10.1080/01944361003766766

Glasgow, T. E., Le, H. T. K., Scott Geller, E., Fan, Y., and Hankey, S. (2019). How Transport Modes, the Built and Natural Environments, and Activities Influence Mood: A GPS Smartphone App Study. J. Environ. Psychol. 66 (May), 101345. doi:10.1016/j.jenvp.2019.101345

Goines, L., and Hagler, L. (2007). Noise Pollution: A Modern Plague. South. Med. J. 100 (3), 287-294. doi:10.1097/smj.0b013e3180318be5

González, M. C., Hidalgo, C. A., and Barabási, A.-L. (2008). Understanding Individual Human Mobility Patterns. Nature 453 (7196), 779-782. doi:10.1038/nature06958

Goodchild, M. F., and Li, W. (2021). Replication across Space and Time Must Be Weak in the Social and Environmental Sciences. Proc. Natl. Acad. Sci. USA 118 (35), e2015759118. doi:10.1073/pnas.2015759118

Güneralp, B., Zhou, Y., Ürge-Vorsatz, D., Gupta, M., Yu, S., Patel, P. L., et al. (2017). Global Scenarios of Urban Density and its Impacts on Building Energy Use through 2050. Proc. Natl. Acad. Sci. U S A. 114 (34), 8945-8950. doi:10.1073/pnas.1606035114

Hartig, T., Evans, G. W., Jamner, L. D., Davis, D. S., and Gärling, T. (2003). Tracking Restoration in Natural and Urban Field Settings. J. Environ. Psychol. 23 (2), 109-123. doi:10.1016/s0272-4944(02)00109-3

Hasanzadeh, K., Laatikainen, T., and Kyttä, M. (2018). A Place-Based Model of Local Activity Spaces: Individual Place Exposure and Characteristics. J. Geographical Syst. 20. doi:10.1007/s10109-017-0264-z

Hasanzadeh, K., Broberg, A., and Kyttä, M. (2017). Where Is My Neighborhood? A Dynamic Individual-Based Definition of home Ranges and Implementation of Multiple Evaluation Criteria. Appl. Geogr. 84, 1-10. doi:10.1016/ j.apgeog.2017.04.006

Heller, A. S., Shi, T. C., Ezie, C. E. C., Reneau, T. R., Travis, R., Baez, L. M., et al. (2020). Association between Real-World Experiential Diversity and Positive Affect Relates to Hippocampal - Striatal Functional Connectivity. Nat. Neurosci. 23, 800-804. doi:10.1038/s41593-020-0636-4

Hillier, B., and Hanson, J. (1984). The Social Logic of Space. Cambridge: Cambridge University Press.

Hillier, B., Koch, D., Marcus, L., and Steen, J. (2009). "Spatial Sustainability in Cities: Organic Patterns and Sustainable Forms," in Proceedings of the 7th International Space Syntax Symposium. Editors D. Koch, L. Marcus, and J. Steen (Stockholm: KTH).

Hillier, B., Yang, T., and Turner, A. (2012). Normalising Least Angle Choice in Depthmap and How it Opens Up New Perspectives on the Global and Local Analysis of City Space. J. Space Syntax 3 (2), 155-193.
Hillier, B., Leaman, A., Stansall, P., and Bedford, M. (1976). Space Syntax. Environ. Plann. B 3 (2), 147-185. doi:10.1068/b030147

Hillier, B., Penn, A., Hanson, J., Grajewski, T., and Xu, J. (1993). Natural Movement: or, Configuration and Attraction in Urban Pedestrian Movement. Environ. Plann. B 20 (1), 29-66. doi:10.1068/b200029

Howard, E. (2007). Garden Cities of to-morrow. Abingdon: Routledge.

Hunter, M. C. R., Gillespie, B. W., and Chen, S. Y. P. (2019). Urban Nature Experiences Reduce Stress in the Context of Daily Life Based on Salivary Biomarkers. Front. Psychol. 10 (APR), 1-16. doi:10.3389/fpsyg.2019.00722

Jacobs, J. (1961). The Death and Life of Great American Cities. New York: Random House.

Javadi, A. H., Emo, B., Howard, L. R., Zisch, F. E., Yu, Y., Knight, R., et al. (2017). Hippocampal and Prefrontal Processing of Network Topology to Simulate the Future. Nat. Commun. 8, 14652. doi:10.1038/ncomms14652

Kaaronen, R. O., and Strelkovskii, N. (2020). Cultural Evolution of Sustainable Behaviors: Pro-environmental Tipping Points in an Agent-Based Model. One Earth 2, 85-97. doi:10.1016/j.oneear.2020.01.003

Kaplan, S., Nielsen, T. A. S., and Prato, C. G. (2016). Walking, Cycling and the Urban Form: A Heckman Selection Model of Active Travel Mode and Distance by Young Adolescents. Transportation Res. D: Transport Environ. 44, 55-65. doi:10.1016/j.trd.2016.02.011

Kong, L., Lau, K. K.-L., Yuan, C., Chen, Y., Xu, Y., Ren, C., et al. (2017). Regulation of Outdoor thermal comfort by Trees in Hong Kong. Sustainable Cities Soc. 31, 12-25. doi:10.1016/j.scs.2017.01.018

Kyttä, M., Broberg, A., Haybatollahi, M., and Schmidt-Thomé, K. (2016). Urban Happiness: Context-Sensitive Study of the Social Sustainability of Urban Settings. Environ. Plann. B Plann. Des. 43, 34-57. doi:10.1177/ 0265813515600121

Le Corbusier (1986). Towards a New Architecture. New York: Dover Publications, Inc.

Lederbogen, F., Kirsch, P., Haddad, L., Streit, F., Tost, H., Schuch, P., et al. (2011). City Living and Urban Upbringing Affect Neural Social Stress Processing in Humans. Nature 474 (7352), 498-501. doi:10.1038/nature10190

Legeby, A. (2013). Patterns of Co-presence: Spatial Configuration and Social Segregation. Stockholm, Sweden: KTH Royal Institute of Technology.

Levin, S. A. (1998). Ecosystems and the Biosphere as Complex Adaptive Systems. Ecosystems 1 (5), 431-436. doi:10.1007/s100219900037

MacKerron, G., and Mourato, S. (2013). Happiness Is Greater in Natural Environments. Glob. Environ. Change 23 (5), 992-1000. doi:10.1016/ j.gloenvcha.2013.03.010

Makse, H. A., Havlin, S., and Stanley, H. E. (1995). Modelling Urban Growth Patterns. Nature 377 (6550), 608-612. doi:10.1038/377608a0

Markevych, I., Schoierer, J., Hartig, T., Chudnovsky, A., Hystad, P., Dzhambov, A. M., et al. (2017). Exploring Pathways Linking Greenspace to Health: Theoretical and Methodological Guidance. Environ. Res. 158 (June), 301-317. doi:10.1016/ j.envres.2017.06.028

Marshall, W. E., and Garrick, N. W. (2010). Effect of Street Network Design on Walking and Biking. Transportation Res. Rec. 2198, 103-115. doi:10.3141/ 2198-12

Marshall, W. E., Piatkowski, D. P., and Garrick, N. W. (2014). Community Design, Street Networks, and Public Health. J. Transport Health 1 (4), 326-340. doi:10.1016/j.jth.2014.06.002

Milgram, S. (1970). The Experience of Living in Cities. Science 167 (3924), 1461-1468. doi:10.1126/science.167.3924.1461

Pan, H., Page, J., Cong, C., Barthel, S., and Kalantari, Z. (2021). How Ecosystems Services Drive Urban Growth: Integrating Nature-Based Solutions. Anthropocene 35, 100297. doi:10.1016/j.ancene.2021.100297

Parthasarathi, P., Hochmair, H., and Levinson, D. (2015). Street Network Structure and Household Activity Spaces. Urban Stud. 52 (6), 1090-1112. doi:10.1177/ 0042098014537956

Pavot, W., and Diener, E. (2013). "Happiness Experienced: The Science of Subjective Well-Being," in Oxford Handbook of Happiness. Editors S. David, I. Boniwell, and A. C. Ayers (Oxford: Oxford University Press). doi:10.1093/ oxfordhb/9780199557257.013.0010

Perry, C. (1929). "The Neighborhood Unit," in Regional Plan of New York and its Environs (New York.

Reeve, A. C., Desha, C., Hargreaves, D., and Hargroves, K. (2015). Biophilic Urbanism: Contributions to Holistic Urban Greening for Urban Renewal. 
Smart Sustainable Built Environ. 4 (2), 215-233. doi:10.1108/sasbe-11-20140057

Samuelsson, K. (2021). Making Space for Resilient Urban Well-Being. University of Gävle.

Samuelsson, K., Colding, J., and Barthel, S. (2019). Urban Resilience at Eye Level: Spatial Analysis of Empirically Defined Experiential Landscapes. Landscape Urban Plann. 187, 70-80. doi:10.1016/j.landurbplan.2019.03.015

Sarkar, C., Webster, C., and Gallacher, J. (2017). Association between Adiposity Outcomes and Residential Density: a Full-Data, Cross-Sectional Analysis of 419562 UK Biobank Adult Participants. Lancet Planet. Health 1 (7), e277-e288. doi:10.1016/s2542-5196(17)30119-5

Schläpfer, M., Dong, L., O'Keeffe, K., Santi, P., Szell, M., Salat, H., et al. (2021). The Universal Visitation Law of Human Mobility. Nature 593 (May), 522-527. doi:10.1038/s41586-021-03480-9

Seto, K. C., Güneralp, B., and Hutyra, L. R. (2012). Global Forecasts of Urban Expansion to 2030 and Direct Impacts on Biodiversity and Carbon Pools. Proc. Natl. Acad. Sci. 109 (40), 16083-16088. doi:10.1073/pnas.1211658109

Shoval, N., Schvimer, Y., and Tamir, M. (2018). Tracking Technologies and Urban Analysis: Adding the Emotional Dimension. Cities 72 (1240), 34-42. doi:10.1016/j.cities.2017.08.005

Simmel, G. (2002). "The metropolis and Mental Life," in The Blackwell City Reader (Oxford and Malden, MA: Wiley-Blackwell), 11-19.

Sisson, P. (2020). How the '15-Minute City' Could Help Post-Pandemic Recovery. Bloomberg CityLab. https://www.bloomberg.com/news/articles/2020-07-15/ mayors-tout-the-15-minute-city-as-covid-recovery. July 16.

Stavroulaki, G., Bolin, D., Berghauser Pont, M., Marcus, L., and Håkansson, E. (2019). "Statistical Modelling and Analysis of Big Data on Pedestrian Movement," in Proceedings of the 12th Space Syntax Symposium, 291-300.
Tan, J., Zheng, Y., Tang, X., Guo, C., Li, L., Song, G., et al. (2010). The Urban Heat Island and its Impact on Heat Waves and Human Health in Shanghai. Int. J. Biometeorol. 54 (1), 75-84. doi:10.1007/s00484-0090256-x

Torku, A., Chan, A. P. C., Yung, E. H. K., and Seo, J. (2021). The Influence of Urban Visuospatial Configuration on Older Adults' Stress: A Wearable Physiological-Perceived Stress Sensing and Data Mining Based-Approach. Building Environ. 206 (August), 108298. doi:10.1016/ j.buildenv.2021.108298

Wirth, L. (1938). Urbanism as a Way of Life. Am. J. Sociol. 44 (1), 1-24. doi:10.1086/217913

Conflict of Interest: The author declares that the research was conducted in the absence of any commercial or financial relationships that could be construed as a potential conflict of interest.

Publisher's Note: All claims expressed in this article are solely those of the authors and do not necessarily represent those of their affiliated organizations, or those of the publisher, the editors and the reviewers. Any product that may be evaluated in this article, or claim that may be made by its manufacturer, is not guaranteed or endorsed by the publisher.

Copyright (C) 2021 Samuelsson. This is an open-access article distributed under the terms of the Creative Commons Attribution License (CC BY). The use, distribution or reproduction in other forums is permitted, provided the original author(s) and the copyright owner(s) are credited and that the original publication in this journal is cited, in accordance with accepted academic practice. No use, distribution or reproduction is permitted which does not comply with these terms. 